\title{
Things We Do for No Reason: Prealbumin Testing to Diagnose Malnutrition in the Hospitalized Patient
}

\author{
Mary Lacy, MD*, Justin Roesch, MD, Jens Langsjoen, MD
}

Department of Internal Medicine, University of New Mexico School of Medicine, Albuquerque, New Mexico.

Inspired by the ABIM Foundation's Choosing Wisely ${ }^{\circledR}$ campaign, the "Things We Do for No Reason" series reviews practices which have become common parts of hospital care but which may provide little value to our patients. Practices reviewed in the TWDFNR series do not represent "black and white" conclusions or clinical practice standards, but are meant as a starting place for research and active discussions among hospitalists and patients. We invite you to be part of that discussion.

\section{CASE PRESENTATION}

A 34-year-old man is admitted for a complicated urinary tract infection related to a chronic in-dwelling Foley catheter. The patient suffered a spinal cord injury at the C4/C5 level as a result of a motor vehicle accident 10 years ago and is confined to a motorized wheelchair. He is an engineer and lives independently but has caregivers. His body mass index (BMI) is $18.5 \mathrm{~kg} / \mathrm{m}^{2}$, and he reports his weight has been stable. He has slight muscle atrophy of the biceps, triceps, interosseous muscles, and quadriceps. The patient reports that he eats well, has no chronic conditions, and has not had any gastrointestinal symptoms (eg, anorexia, nausea, diarrhea) over the last six months. You consider whether to order a serum prealbumin test to assess for possible malnutrition.

\section{BACKGROUND}

The presence of malnutrition in hospitalized patients is widely recognized as an independent predictor of hospital mortality. ${ }^{1}$ According to the American Society for Parenteral and Enteral Nutrition (ASPEN), malnutrition is defined as "an acute, subacute or chronic state of nutrition, in which varying degrees of overnutrition or undernutrition with or without inflammatory activity have led to a change in body composition and diminished function." 2 In one large European study, patients screening positive for being at risk of malnutrition had a 12-fold increase in hospital mortality. ${ }^{1}$

Inpatient malnutrition is remarkably underdocumented. Studies using chart reviews have found a prevalence of malnutrition in hospitalized patients of between $20 \%$ and $50 \%$, and

*Corresponding Author: Mary Lacy, MD, MSC; E-mail: melacy@salud.unm. edu; Telephone: 505-925-0660.

Published online first October 31, 2018.

Received: March 30, 2018; Revised: August 2, 2018;

Accepted: August 19, 2018

() 2019 Society of Hospital Medicine DOI 10.12788/jhm. 3088 only $3 \%$ of hospital discharges are associated with a diagnostic code for malnutrition. ${ }^{3-5}$ Appropriate diagnosis and documentation of malnutrition is important given the profound prognostic and management implications of a malnutrition diagnosis. Appropriate documentation benefits health systems as malnutrition documentation increases expected mortality, thereby improving the observed-to-expected mortality ratio.

Serum prealbumin testing is widely available and frequently ordered in the inpatient setting. In a query we performed of the large aggregate Cerner Electronic Health Record database, HealthFacts, which includes data from inpatient encounters for approximately 700 hospitals in the United States, prealbumin tests were ordered 129,152 times in 2015. This activity corresponds to estimated total charges of $\$ 2,562,375$ based on the 2015 clinical laboratory fee schedule. ${ }^{6}$

\section{WHY YOU MIGHT THINK PREALBUMIN DIAGNOSES MALNUTRITION}

Prealbumin is synthesized in the liver and released into circulation prior to excretion by the kidneys and gastrointestinal tract. Prealbumin transports thyroxine, triiodothyronine, and holo-retinol binding protein and, as a result, is also known as transthyretin. ' It was first proposed as a nutritional marker in 1972 with the publication of a study that showed low levels of prealbumin in 40 children with kwashiorkor that improved with intensive dietary supplementation. ${ }^{8}$ The shorter half-life of prealbumin ( 2.5 days) as compared with other identified nutritional markers, such as albumin, indicate that it would be suitable for detecting rapid changes in nutritional status.

\section{WHY PREALBUMIN IS NOT HELPFUL FOR DIAGNOSING MALNUTRITION}

Prealbumin Is Not Specific

An ideal nutritional marker should be specific enough that changes in this marker reflect changes in nutritional status. ${ }^{9}$ While there are many systemic factors that affect nutritional markers, such as prealbumin (Table 1), the acute phase response triggered by inflammation is the most significant confounder in the acutely ill hospitalized patient..$^{9}$ This response to infection, stress, and malignancy leads to an increase in proinflammatory cytokines, increased liver synthesis of inflammatory proteins, such as C-reactive protein (CRP), and increased vascular permeability. Prealbumin is a negative acute phase reactant that decreases in concentration during the stress response due to slowed synthesis and extravasation. ${ }^{9}$ In a study of 24 patients with severe sepsis and trauma, levels of prealbumin in- 
TABLE 1. Factors Affecting Prealbumin ${ }^{7}$

\begin{tabular}{ll}
\hline Increased by: & Decreased by: \\
\hline Exogenous corticosteroids & Acute phase response \\
NSAIDS & Malnutrition \\
Renal failure & Liver disease \\
Dehydration & Thyroid disease \\
& Hemodilution \\
& Nephrotic syndrome \\
& Protein-losing enteropathy \\
& Acute blood loss \\
\hline
\end{tabular}

Abbreviation: NSAIDs, nonsteroidal anti-inflammatory drugs

versely correlated with CRP, a reflection of the stress response, and returned to normal when CRP levels normalized. Neither prealbumin nor CRP, however, correlated with total body protein changes..$^{10}$ Unfortunately, many studies supporting the use of prealbumin as a nutritional marker do not address the role of the acute phase response in their results. These studies include the original report on prealbumin in kwashiorkor, a condition known to be associated with a high rate of infectious diseases that can trigger the acute phase response. ${ }^{9} \mathrm{~A}$ consensus statement from the Academy of Nutrition and Dietetics (AND) and ASPEN noted that prealbumin is an indicator of inflammation and lacks the specificity to diagnose malnutrition. ${ }^{11}$

\section{Prealbumin Is Not Sensitive}

A sensitive laboratory test for malnutrition should allow for detection of malnutrition at an early stage. ${ }^{9}$ However, patients who demonstrate severe malnutrition without a coexisting inflamma- tory state do not consistently show low levels of prealbumin. In a systematic review of 20 studies in nondiseased malnourished patients, only two studies, both of which assessed patients with anorexia nervosa, had a mean prealbumin below normal $(<20$ $\mathrm{mg} / \mathrm{dL}$ ), and this finding corresponded to patient populations with mean BMls less than $12 \mathrm{~kg} / \mathrm{m}^{2}$. More importantly, normal prealbumin levels were seen in groups of patients with a mean $\mathrm{BMI}$ as low as $12.9 \mathrm{~kg} / \mathrm{m}^{2} .^{12}$ Analysis by AND found insufficient evidence to support a correlation between prealbumin and weight loss in anorexia nervosa, calorie restricted diets, or starvation. ${ }^{13}$ The data suggest that prealbumin lacks sufficient sensitivity to consistently detect cases of malnutrition easily diagnosed by history and/or physical exam.

\section{Prealbumin Is Not Consistently Responsive to Nutri- tional Interventions}

An accurate marker for malnutrition should improve when nutritional intervention results in adequate nutritional intake. ${ }^{9}$ While some studies have shown improvements in prealbumin in the setting of a nutritional intervention, many of these works are subject to the same limitations related to specificity and lack of control for concurrent inflammatory processes. In a retrospective study, prealbumin increased significantly in 102 patients receiving TPN for one week. Unfortunately, patients with renal or hepatic disease were excluded, and the role of inflammation was not assessed. ${ }^{14}$ Institutionalized patients with Alzheimer's disease and normal CRP levels showed a statistically significant increase in weight gain, arm muscle circumference, and triceps skin-fold thickness following a nutritional program without a notable change in prealbumin. ${ }^{15}$ In a study assessing the relationship of prealbumin, CRP, and nutritional intake, critically ill popu-

TABLE 2. Comparison of Diagnostic Tools for Malnutrition ${ }^{a}$

\begin{tabular}{|c|c|c|}
\hline & AND/ASPEN"11 & ESPEN $^{18}$ \\
\hline \multicolumn{3}{|l|}{ Historical Variables } \\
\hline Change in weight & Weight loss (\% over time) & Weight loss $>10 \%$ indefinite of time or $>5 \%$ over the last 3 months \\
\hline Intake behaviors & Insufficient energy intake & NA \\
\hline \multicolumn{3}{|l|}{ Physical Examination Variables } \\
\hline Body fat & Loss of body fat & Fat-free mass index (FFMI) <15 (women) or 17 kg/m² (men) \\
\hline Muscle mass & Loss of muscle mass & NA \\
\hline BMI & NA & $\mathrm{BMI}<20 \mathrm{~kg} / \mathrm{m}^{2}$ if $<70$ years of age, or $<22 \mathrm{~kg} / \mathrm{m}^{2}$ if $>70$ years of age \\
\hline Other exam findings & Fluid accumulation & NA \\
\hline Functional capacity impairment & Reduced grip strength & NA \\
\hline Additional information & Graded by severity and acuity & Graded by acuity \\
\hline Criteria for diagnosis & Two of 6 criteria required & $\begin{array}{l}\mathrm{BMI}<18.5 \mathrm{~kg} / \mathrm{m}^{2 \mathrm{~b}} \\
\text { Or } \\
\text { Weight changes combined with either body fat or BMI }\end{array}$ \\
\hline
\end{tabular}

${ }^{a}$ Elements of diagnostic criteria are discussed. Each guideline or assessment tool requires a certain number of criteria to be met to establish a diagnosis

${ }^{\mathrm{b}} \mathrm{BMI}<18.5 \mathrm{~kg} / \mathrm{m}^{2}$ is a solitary criterion based on World Health Organization recommendations

Abbreviations: AND, Academy of Nutrition and Dietetics; ASPEN, American Society for Parenteral and Enteral Nutrition; BMI, body mass index; ESPEN, European Society for Clinical Nutrition and Metabolism; NA, not applicable. 
lations receiving less than or greater than $60 \%$ of their estimated caloric needs showed no significant difference in prealbumin. In fact, prealbumin levels were only correlated with CRP levels. ${ }^{16}$ This finding argues against the routine use of prealbumin for nutrition monitoring in the acutely ill hospitalized patient.

\section{Prealbumin Is Not Consistently Correlated with Health Outcomes}

Even if prealbumin increased consistently in response to nutritional intervention, whether this change corresponds to an improvement in clinical outcomes has yet to be demonstrated. ${ }^{9}$ In 2005, Koretz reviewed 99 clinical trials and concluded that even when changes in nutritional markers are seen with nutritional support, the "changes in nutritional markers do not predict clinical outcomes." 17

\section{WHAT YOU SHOULD DO INSTEAD: USE NON- BIOLOGIC METHODS FOR SCREENING AND DIAGNOSING MALNUTRITION}

Given the lack of a suitable biologic assay to identify malnutrition, dieticians and clinicians must rely on other means to assess malnutrition. Professional societies, including ASPEN and the European Society for Clinical Nutrition and Metabolism, have proposed different guidelines for the screening and assessment of malnutrition (Table 2). ${ }^{11,18}$ In 2016, these organizations, along with the Latin American Federation of Nutritional Therapy, Clinical Nutrition, and Metabolism and the Parenteral and Enteral Nutrition Society of Asia, formed The Global Leadership Initiative on Malnutrition (GLIM). In 2017, the GLIM taskforce agreed on clinically relevant diagnostic variables for the screening and assessment of malnutrition, including reduced food intake (anorexia), nonvolitional weight loss, (reduced) lean mass, status of disease burden and inflammation, and low body mass index or underweight status. ${ }^{19}$

\section{RECOMMENDATIONS}

- Do not use prealbumin to screen for or diagnose malnutrition.

- Consult with local dietitians to ensure that your institutional approach is in agreement with consensus recommendations.

\section{CONCLUSION}

In revisiting the case above, the patient does not have clear evidence of malnutrition based on his history (stable weight and good reported nutritional intake), although he does have a low $\mathrm{BMI}$ of $18.5 \mathrm{~kg} / \mathrm{m}^{2}$. Rather than prealbumin testing, which would likely be low secondary to the acute phase response, he would better benefit from a nutrition-focused history and physical exam.

The uncertainties faced by clinicians in diagnosing malnutrition cannot readily be resolved by relying on a solitary laboratory marker (eg, prealbumin) or a stand-alone assessment protocol. The data obtained reflect the need for multidisciplinary teams of dieticians and clinicians to contextualize each patient's medical history and ensure that the selected metrics are used appropriately to aid in diagnosis and documentation. We advocate that clinicians not routinely use prealbumin to screen for, confirm the diagnosis of, or assess the severity of malnutrition in the hospitalized patient.
Do you think this is a low-value practice? Is this truly a "Thing We Do for No Reason?" Share what you do in your practice and join in the conversation online by retweeting it on Twitter (\#TWDFNR) and liking it on Facebook. We invite you to propose ideas for other "Things We Do for No Reason" topics by emailingTWDFNR@hospitalmedicine.org.

Disclosures: The authors have nothing to disclose.

\section{References}

1. Sorensen J, Kondrup J, Prokopowicz J, et al. EuroOOPS: an international, multicentre study to implement nutritional risk screening and evaluate clinical outcome. Clin Nutr Edinb Scotl. 2008;27(3):340-349. doi: 10.1016/j. clnu.2008.03.012.

2. Mueller C, Compher C, Ellen DM, American Society for Parenteral and Enteral Nutrition (A.S.P.E.N.) Board of Directors. A.S.P.E.N. clinical guidelines: nutrition screening, assessment, and intervention in adults. JPEN J Parenter Enteral Nutr. 2011;35(1):16-24. doi: 10.1177/0148607110389335.

3. Kaiser MJ, Bauer JM, Rämsch $\mathrm{C}$, et al. Frequency of malnutrition in older adults: a multinational perspective using the mini nutritional assessment. $J$ Am Geriatr Soc. 2010;58(9):1734-1738. doi: 10.1111/j.1532-5415.2010.03016.x.

4. Robinson MK, Trujillo EB, Mogensen KM, Rounds J, McManus K, Jacobs DO. Improving nutritional screening of hospitalized patients: the role of prealbumin. JPEN J Parenter Enteral Nutr. 2003;27(6):389-395; quiz 439. doi: 10.1177/0148607103027006389.

5. Corkins MR, Guenter P, DiMaria-Ghalili RA, et al. Malnutrition diagnoses in hospitalized patients: United States, 2010. JPEN J Parenter Enteral Nutr. 2014;38(2):186-195. doi: 10.1177/0148607113512154.

6. Clinical Laboratory Fee Schedule Files. cms.org. https://www.cms.gov/Medicare/Medicare-Fee-for-Service-Payment/ClinicalLabFeeSched/Clinical-Laboratory-Fee-Schedule-Files.html. Published September 29, 2016. Accessed January 5, 2018

7. Myron Johnson A, Merlini G, Sheldon J, Ichihara K, Scientific Division Committee on Plasma Proteins (C-PP), International Federation of Clinical Chemistry and Laboratory Medicine (IFCC). Clinical indications for plasma protein assays: transthyretin (prealbumin) in inflammation and malnutrition. Clin Chem Lab Med. 2007;45(3):419-426. doi: 10.1515/CCLM.2007.051.

8. Ingenbleek Y, De Visscher M, De Nayer P. Measurement of prealbumin as index of protein-calorie malnutrition. Lancet. 1972;2(7768):106-109. doi: 10.1016/S0140-6736(72)91596-6.

9. Barbosa-Silva MCG. Subjective and objective nutritional assessment methods: what do they really assess? Curr Opin Clin Nutr Metab Care. 2008;11(3):248-254. doi: 10.1097/MCO.0b013e3282fba5d7

10. Clark MA, Hentzen BTH, Plank LD, Hill GL. Sequential changes in insulin-like growth factor 1, plasma proteins, and total body protein in severe sepsis and multiple injury. J Parenter Enter Nutr. 1996;20(5):363-370. doi: 10.1177/0148607196020005363.

11. White JV, Guenter P, Jensen G, et al. Consensus statement of the Academy of Nutrition and Dietetics/American Society for Parenteral and Enteral Nutrition: characteristics recommended for the identification and documentation of adult malnutrition (undernutrition). J Acad Nutr Diet. 2012;112(5):730-738. doi: 10.1016/j.jand.2012.03.012.

12. Lee JL, Oh ES, Lee RW, Finucane TE. Serum albumin and prealbumin in calorically restricted, nondiseased individuals: a systematic review. Am J Med. 2015;128(9):1023.e1-22. doi: 10.1016/j.amjmed.2015.03.032.

13. Academy of Nutrition and Dietetics Evidence Analysis Library. Nutrition Screening (NSCR) Systematic Review (2009-2010). https://www.andeal.org/ tmp/pdf-print-919C51237950859AE3E15F978CEF49D8.pdf. Accessed August 23, 2017.

14. Sawicky CP, Nippo J, Winkler MF, Albina JE. Adequate energy intake and improved prealbumin concentration as indicators of the response to total parenteral nutrition. J Am Diet Assoc. 1992;92(10):1266-1268.

15. Van Wymelbeke V, Guédon A, Maniere D, Manckoundia P, Pfitzenmeyer P. A 6-month follow-up of nutritional status in institutionalized patients with Alzheimer's disease. J Nutr Health Aging. 2004;8(6):505-508

16. Davis CJ, Sowa D, Keim KS, Kinnare K, Peterson S. The use of prealbumin and $C$-reactive protein for monitoring nutrition support in adult patients receiving enteral nutrition in an urban medical center. JPEN J Parenter Enteral Nutr. 2012;36(2):197-204. doi: 10.1177/0148607111413896.

17. Koretz RL. Death, morbidity and economics are the only end points for trials. Proc Nutr Soc. 2005;64(3):277-284. doi: 10.1079/PNS2005433

18. Cederholm T, Bosaeus I, Barazzoni R, et al. Diagnostic criteria for malnutrition - an ESPEN consensus statement. Clin Nutr Edinb Scotl. 2015;34(3):335340. doi: 10.1016/j.clnu.2015.03.001.

19. Jensen GL, Cederholm T. Global leadership initiative on malnutrition: progress report from ASPEN clinical nutrition week 2017. JPEN J Parenter Enteral Nutr. April 2017:148607117707761. doi: 10.1177/0148607117707761. 